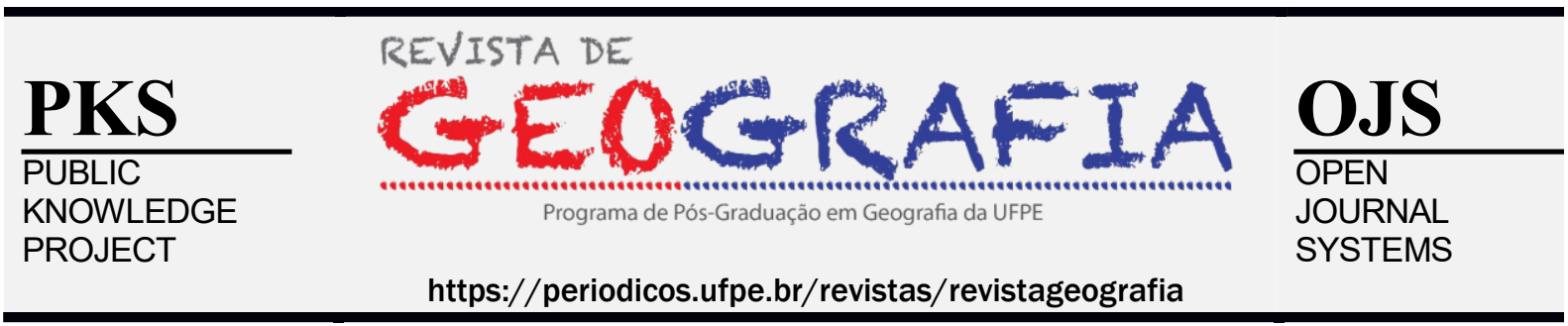

\title{
ESPAÇOS LIVRES DE EDIFICAÇÃO E COBERTURA VEGETAL NO BAIRRO VILA DOS COMERCIÁRIOS - PARANAGUÁ-PR
}

\author{
Sthefany Caroline Alves da Silva ${ }^{1}$, Rafaele Conceição dos Santos Alves ${ }^{2}$, Emerson Luis \\ Tonetti $^{3}$, Gislaine Garcia de Faria ${ }^{4}$, Emerson Luís Pawoski da Silva ${ }^{5}$
}

\author{
${ }^{1}$ Instituto Federal do Paraná, E-mail: sthecaroline29@gmail.com, ORCID: http://orcid.org/0000-0001-6022- \\ 8574 \\ ${ }^{2}$ Instituto Federal do Paraná, E-mail: rahsnts16@gmail.com, ORCID: http://orcid.org/0000-0002-4703-0309 \\ ${ }^{3}$ Instituto Federal do Paraná, E-mail: emerson.tonetti@ifpr.edu.br, ORCID: http://orcid.org/0000-0003-3325- \\ 0615 \\ ${ }^{4}$ Instituto Federal do Paraná, E-mail: gisa.faria@ifpr.edu.br, ORCID: http://orcid.org/0000-0002-8927-0933 \\ ${ }^{5}$ Universidade Federal do Paraná, E-mail: em.pawoski@gmail.com, ORCID: http://orcid.org/0000-0003-1355- \\ 8698
}

Artigo recebido em 04/05/2020 e aceito em 04/10/2021

\begin{abstract}
RESUMO
A presença de Cobertura Vegetal em áreas urbanas é um importante componente da qualidade ambiental. Além da vegetação, os Espaços de Uso Público e Livres de Edificação (EUPLEs) devem ser planejados para atender toda a comunidade, para que se sintam atraídos a se deslocarem de suas residências até estes locais para práticas de atividades física ou recreação. O presente trabalho tem como objetivo levantar a quantidade e a distribuição dos EUPLEs e Cobertura Vegetal no bairro Vila dos Comerciários na área urbana da cidade de Paranaguá na região costeira do Paraná. A partir do software Google Earth Pro, foi realizada a sobreposição do limite do bairro, delimitando-se as coberturas vegetais arbóreas e herbáceas, e EUPLEs presentes no bairro. A partir dos resultados obteve-se 7,1\% de cobertura vegetal no bairro e 2 espaços para o lazer. Posteriormente, uma carta temática foi elaborada a partir do software QGIS, sendo possível demonstrar que o bairro Vila dos Comerciários não possui um planejamento adequado que proporcione aos seus moradores um bem-estar físico e ambiental. Os EUPLEs localizados no bairro não possuem infraestrutura que atendam às necessidades de lazer e benefícios que agregam a qualidade de vida de seus residentes.
\end{abstract}

Palavras-chave: Qualidade ambiental; Planejamento urbano; Lazer. 


\title{
ESPAÇOS LIVRES DE EDIFICAÇÃO E COBERTURA VEGETAL NO BAIRRO VILA DOS COMERCIÁRIOS - PARANAGUÁ-PR
}

\begin{abstract}
The presence of Vegetal Cover on urban areas is an important component of environmental quality. In addition to the vegetation, Public Spaces With No Buildings (PSWNBs) must be planned to serve the entire community, to attract people to move from their homes to these places for physical activity or recreation. The present work aims to survey the quantity and distribution of PSWNBs and Vegetal Cover on the Vila dos Comerciários's neighborhood of the urban area of the city Paranaguá in the coastal region of Paraná. The neighborhood boundary was superimposed using the Google Earth Pro software and delimiting the tree and herbaceous vegetable coverings and EUPLEs present in the neighborhood. From the results, $7.1 \%$ of vegetal cover was obtained on the neighborhood. A thematic map was prepared using the QGIS software, and was possible to identify that Vila dos Comerciários doesn't have adequate planning to provides physical and environmental well-being to its residents. PSWNBs located on the neighborhood don't have infrastructure that offers the leisure needs and benefits that add to the quality of life of its residents.
\end{abstract}

Keywords: Environmental Quality; Urban Planning; Recreation.

\section{INTRODUÇÃO}

Mudanças nas dinâmicas ambientais que afetam o bem estar da sociedade estão comumente atreladas ao avanço das áreas urbanizadas (LATOUR, 2013). Contudo, mesmo com tantas interferências do ser humano sobre a natureza, estas áreas podem ser consideradas sistemas onde os processos físicos, químicos e biológicos não deixam de existir, pois todas as suas partes são interligadas e interdependentes, consequentemente, uma mudança em uma parte da cidade resulta em mudanças em outras, como comentam Esteves e Nucci (2015). No entanto, tais processos não ocorrem de forma semelhante aos sistemas naturais, com a tendência para autorregulação dinâmica e otimização do uso da matéria e da energia disponíveis (ADLER; TUNNER, 2015).

A concentração de pessoas e edificações, impermeabilização das superfícies, alto consumo de matéria e energia entre outras características urbanas provocam uma série de efeitos no ambiente, com perdas significativas da qualidade, como as alterações no clima local, no ciclo da água, no aumento da poluição e na perda dos espaços para o lazer e cobertura vegetal (NUCCI, 2008).

Nucci (2008) destaca a importância da qualidade dos espaços livres em relação às questões de tamanho, manutenção, localização em relação ao tráfego e a distância da residência entre outras questões que devem ser consideradas para garantir a função e o valor 
socioambiental destas áreas. Outro indicador muito importante, porém negligenciado, no desenvolvimento das cidades é a cobertura vegetal (CAVALHEIRO et al., 1999).

As plantas são componentes importantes das paisagens urbanas pelos benefícios que desempenham, como a melhoria do conforto térmico, elevação da umidade relativa do ar, redução dos níveis de poeira e ruído entre tantos outros (NUCCI, 2008). No planejamento e na gestão dessas áreas os dados sobre a quantidade, a qualidade e a distribuição da vegetação, são fundamentais para o desenvolvimento de ambientes que valorizam a qualidade para satisfazer as necessidades do cidadão (NUCCI, 2008, MOURA; NUCCI, 2008).

Sukopp e Werner (1991) propuseram que 33\% das áreas urbanas centrais deveriam ser permeáveis, não edificadas e cobertas por vegetação com ampla conexão com a zona rural. Attwell (2000), recomendou os seguintes índices de cobertura vegetal: 50\% em áreas residenciais pouco verticalizadas, sendo $25 \%$ de árvores e arbustos; $30 \%$ para as áreas ocupadas por complexo de apartamentos, sendo 15\% para árvores e arbustos; $20 \%$ para as áreas industriais com 10\% para árvores e arbustos.

Tais proposições resultam da busca por espaços que satisfaçam necessidades como a do lazer e da manutenção dos processos ecológicos. Desta forma, os espaços livres, como praças, e a presença de vegetação nos bairros são fundamentais para atender os moradores. Além disso, esses locais contribuem diretamente com a qualidade do ambiente, podendo favorecer o conforto térmico com a redução da temperatura do entorno, a diminuição de ruídos e poluentes no ar, também, a redução de alagamentos com a redução do runnoff e aumento da infiltração da água no solo (ROSIN; BENINI, 2018).

Nesse sentido, com o crescimento acelerado das cidades, existe a tendência para a redução dos espaços de lazer e da presença da vegetação nas paisagens urbanizadas (ESTEVES; NUCCI; VALASKI, 2014). Existem recomendações de distância máxima para a presença de equipamentos públicos em relação a residência, entre outras recomendações. Por exemplo, uma área de lazer para crianças deve estar no máximo a 200m de distância da residência (BARTON; TSOUROU, 2000).

Buccheri-Filho (2012) após análise da evolução do conceito espaço livre de edificação, destaca a possibilidade deste ser público ou privado e ainda, conter ou não vegetação, propondo os conceitos Espaços de Uso Público e Livres de Edificação com Vegetação (EUPLEVs) e sem vegetação (EUPLEs). Esses espaços podem indicar a presença ou diminuição da qualidade ambiental e servir de referência aos cidadãos e planejadores públicos ao considerar que quando 
estas características não estão presentes no bairro, os moradores tem que se deslocar de suas casas para o lazer e atividades diárias. Desta maneira usam transporte motorizado e contribuem com a emissão de gases estufa e congestionamento das vias ao utilizarem o próprio carro e na ausência de um veículo próprio, se estressam ao enfrentarem as dificuldades do transporte público. Em alguns casos, há pouca locomoção e isso potencializa o aumento das doenças relacionadas com o sedentarismo. Por isso é necessário que todos os bairros tenham EUPLEs, preferencialmente com vegetação (BUCCHERI-FILHO, 2012; ROSIN; BENINI, 2018).

A disponibilidade dos espaços livres com qualidade e nas proximidades das residências além de desempenharem funções de lazer, mesmo que restrita a determinadas faixas etárias da população podem desempenhar funções ecológicas importantes, mesmo que não contenham a vegetação. Locais como as praças, largos de igrejas, campos de jogos de areia, por exemplo, podem atuar na infiltração da água no solo e podem reter temporariamente a água das chuvas reduzindo o volume de água escoado superficialmente e, consequentemente, reduzir as chances de alagamentos. A multifuncionalidade dos espaços urbanos é um ponto importante no trabalho de Hough (1998), Herzog (2013) e Ahern (2013).

Um EUPLE, de certa forma, auxilia na instalação dos espaços com funções sociais e ambientais, previstos pelo Estatuto da Cidade (BRASIL, 2008). Cada EUPLE atende demandas específicas de certos segmentos da população. Os campos de jogos e os playgrounds, por exemplo, atendem mais adolescentes e crianças, respectivamente. Em vista disso, ressalta a importância da diversidade desses espaços para atender todos os segmentos da população, além das questões relacionadas com a qualidade e a distância da residência e a multifuncionalidade.

Misael (2019) propõe o raio de 300m do centro do EUPLE para delimitar sua área de influência, ou seja, a população atendida por esses espaços. Os locais que não estivessem sob essa faixa de ação não estariam sendo contemplados com a distância mínima requerida para facilitar a acessibilidade e o atendimento da necessidade do cidadão. Desta forma, podem ser reconhecidos os vazios urbanos de EUPLEs.

Espaços para o lazer e a presença da vegetação são cada vez mais difíceis de serem encontrados nas proximidades das residências. Na implantação e desenvolvimento dos bairros muitas vezes essas condições não recebe a devida consideração (ADLER; TANNER, 2015). No município de Paranaguá, na região litorânea do Estado do Paraná, esta é uma situação comum em diversos bairros. Sendo o resultado de um crescimento espontâneo e rápido das áreas urbanas nas últimas décadas, sobretudo vinculados ao desenvolvimento e expansão das 
atividades portuárias do Porto Dom Pedro II ou porto de Paranaguá, como é mais conhecido (CUNICO, 2016).

Paranaguá, localizada no litoral, é a cidade mais antiga do Paraná. No passado o núcleo urbano estruturava-se nas imediações da atual Igreja Matriz e da Fonte Velha, e do antigo porto nas margens do Rio Itiberê. No início do século 20, porém, com a expansão das atividades portuárias um novo porto foi construído na baía de Paranaguá, sendo o atual Porto Dom Pedro II. Neste entorno novas áreas foram urbanizadas, mas sem o deslocamento do comércio. $\mathrm{O}$ centro histórico e comercial persiste e ainda hoje polariza tanto as funções econômicas da cidade quanto de toda a região (TRAMUJAS, 1996; IPHAN, 2009). No caso de Paranaguá, há a tendência para concentração dos espaços de lazer nos bairros mais antigos e centrais (TONETTI; NUCCI; VALASKI, 2012) e da presença da vegetação nas áreas periféricas, nas proximidades com os manguezais (TONETTI; NUCCI; CRUZ-JUNIOR, 2011). Isto contraria as recomendações de Barton e Tsourou (2000) para a obtenção de cidades saudáveis.

Diante deste contexto, o presente trabalho de pesquisa teve o objetivo de levantar a quantidade e a distribuição dos Espaços de Uso Público e Livres de Edificações e da Cobertura Vegetal no bairro Vila dos Comerciários na área urbana do município de Paranaguá na região costeira do Paraná. O presente texto apresenta como suporte teórico os estudos sobre a Paisagem e a importância do planejamento municipal voltados a valorização ambiental e consequente qualidade de vida.

\section{METODOLOGIA}

Área de Estudo

A região costeira do Paraná apresenta grande valor como patrimônio natural para proteção da biodiversidade pela presença de remanescentes em bom estado de conservação da Mata Atlântica. Politicamente esse território está dividido em sete municípios, sendo Paranaguá e Antonina com predomínio de atividades portuárias, Guaratuba, Matinhos e Pontal do Paraná como balneários urbanos, Guaraqueçaba e Morretes, predominantemente agrícolas (CUNICO,2016). 
Esses municípios se encontram sob influência das massas de ar quentes e úmidas do Oceano Atlântico, e tem um clima subtropical marcado pela temperatura acima de $30^{\circ}$ e precipitação acima de $60 \mathrm{~mm}^{3} /$ dia em meses quentes porque concentram e intensificam essas massas devido ao relevo acidentado e grande taxa de convecção (CAVALCANTI; FERREIRA, 2021). O município de Paranaguá (Figura 1) no litoral do Estado do Paraná, abrange um território com $808,959 \mathrm{~km}^{2}$, a população estimada é de 154.936 habitantes, concentrados na área urbana, conferindo um grau de urbanização de 96,38\% (IPARDES, 2020).
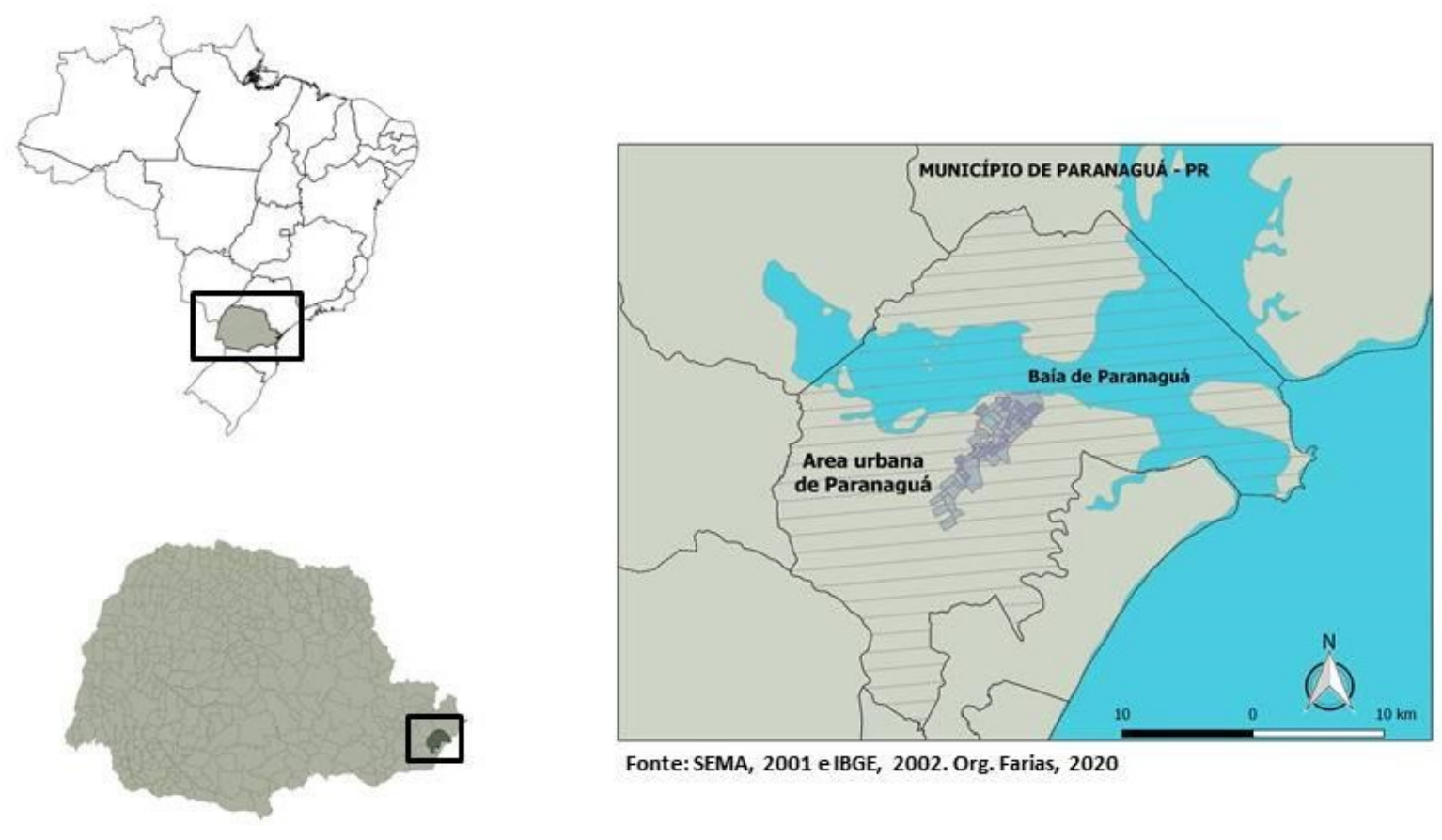

Figura 1 - Localização de Paranaguá

Fonte: os autores.

Os primeiros assentamentos da cidade ocorreram nas zonas costeiras, com desbravamento gradual dos territórios carijós já nos primeiros 50 anos da chegada de imigrantes europeus. Nesse tempo, Paranaguá era utilizada para extração de minérios e como rota fluvial ao interior do continente para pessoas, equipamentos e materiais (TRAMUJAS, 1996, CAVAZZANI; GOMES, 2017). Paranaguá, originalmente denominada de Pernaguá (grande mar redondo) na língua Tupi-Guarani, teve inicialmente o porto e as primeiras habitações instaladas nas margens do Rio Itiberê. Posteriormente, a necessidade de expansão das atividades portuárias conduziu a construção do Porto Dom Pedro II, na Baía de Paranaguá, em 1935. Com este evento, novas áreas sofreram processo de urbanização (SANTOS, 1952; TRAMUJAS, 1996). 
Sendo uma cidade portuária, tem no porto sua principal atividade de movimentação econômica, constituindo-se como polo regional. A área urbanizada se desenvolveu sobre antigos depósitos quaternários de sedimento marinho e de sedimentos recentes de manguezais e margem de rios (CUNICO, 2016), dos quais muitos se caracterizam como ambientes vulneráveis de Áreas de Preservação Permanente (APP), de acordo com o atual Código Florestal Brasileiro (BRASIL, 2012), gerando inúmeros conflitos socioambientais.

O bairro Vila dos Comerciários (Figura 2), localizado nas coordenadas 255'09"S, $48^{\circ} 56^{\prime} 52^{\prime \prime} \mathrm{W}$, selecionado para esta pesquisa é predominantemente residencial e possui densidade populacional variando de 50 a 250 habitantes por hectare, o seu planejamento e consolidação ocorreu na década de 1980 segundo a evolução da ocupação urbana presente no Plano Diretor Municipal (PARANAGUÁ, 2007), diferentemente do que aconteceu em outros bairros do município que não tiveram essa possibilidade de planejamento. Sendo considerado um dos mais novos bairros da cidade, a Vila dos Comerciários advém da expansão urbana em direção ao interior do continente. Em decorrência de sua recente fundação, é uma área de estudo ainda pouco analisada (SILVA; FARIA, 2019). No entanto, as observações trazidas por esse trabalho demonstraram excesso de impermeabilização e aglomeração de edificações em pontos específicos. Demonstrando ausência de algum controle do crescimento/desenvolvimento no local.

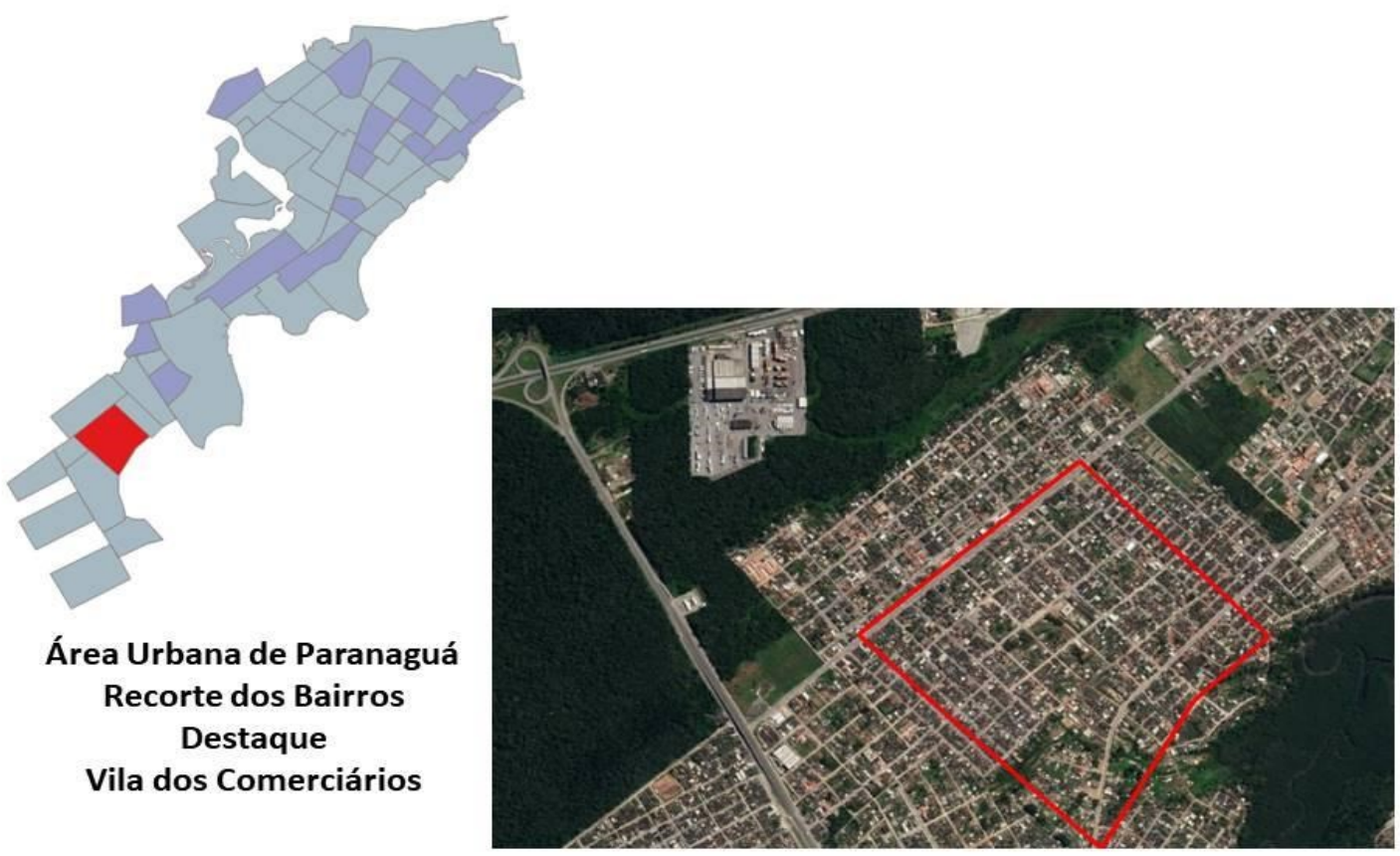

Figura 2 - Imagem do bairro Vila dos Comerciários (contorno vermelho, BR277 - acima e PR407 - lado esquerdo, lado direito - margens do Rio da Vila, afluente do Rio Itiberê).

Fonte: Prefeitura Municipal de Paranaguá e Google Earth Pro. 


\section{Procedimentos adotados}

O estudo foi dividido em duas etapas: a observação das pesquisas anteriores na literatura sobre a paisagem e espaços públicos da cidade de Paranaguá para obter-se um entendimento geral e verificação de cobertura vegetal e EUPLEs no bairro Vila dos Comerciários vinculadas a qualidade ambiental e lazer.

Para a etapa do bairro Vila dos Comerciários foi utilizado o Google Earth Pro ${ }^{\circledR}$ para identificar EUPLEs e vegetação. Tendo como base a proposição de Attwell (2000), apenas duas classes de cobertura vegetal (CAVALHEIRO, 1999) foram compostas, indicando o predomínio fisionômico de vegetação arbórea na primeira e de herbáceas na segunda. Estas foram distintas na imagem pelas diferenças de cor e textura (COVIZZI; CAMARGO; GOBBI, 2017). Visitas in loco foram realizadas para confirmação dos EUPLEs. No $Q$-GIS foi elaborado o resultado em forma de carta temática e tabela de valores absolutos e percentuais das classes de cobertura vegetal presentes no bairro.

\section{RESULTADOS E DISCUSSÃO}

Os espaços de Paranaguá

No município de Paranaguá, Tonetti, Nucci e Valaski (2012) encontraram 41 EUPLEs na área urbana mais consolidada do município (Figura 3). Neste estudo seguiu-se a recomendação de Barton e Tsourou (2000) de que todos os residentes possam alcançar um espaço de lazer em até 15 minutos de caminhada, o que equivaleria a 300m de distância ou no máximo 4 quadras que separariam a residência do EUPLE. Os autores encontraram inúmeras áreas não atendidas pelo sistema de lazer presente no local estudado e em certos locais a presença de vias com tráfego intenso e desprovidas de semáforos, atuavam como barreiras para a utilização dos EUPLEs. 


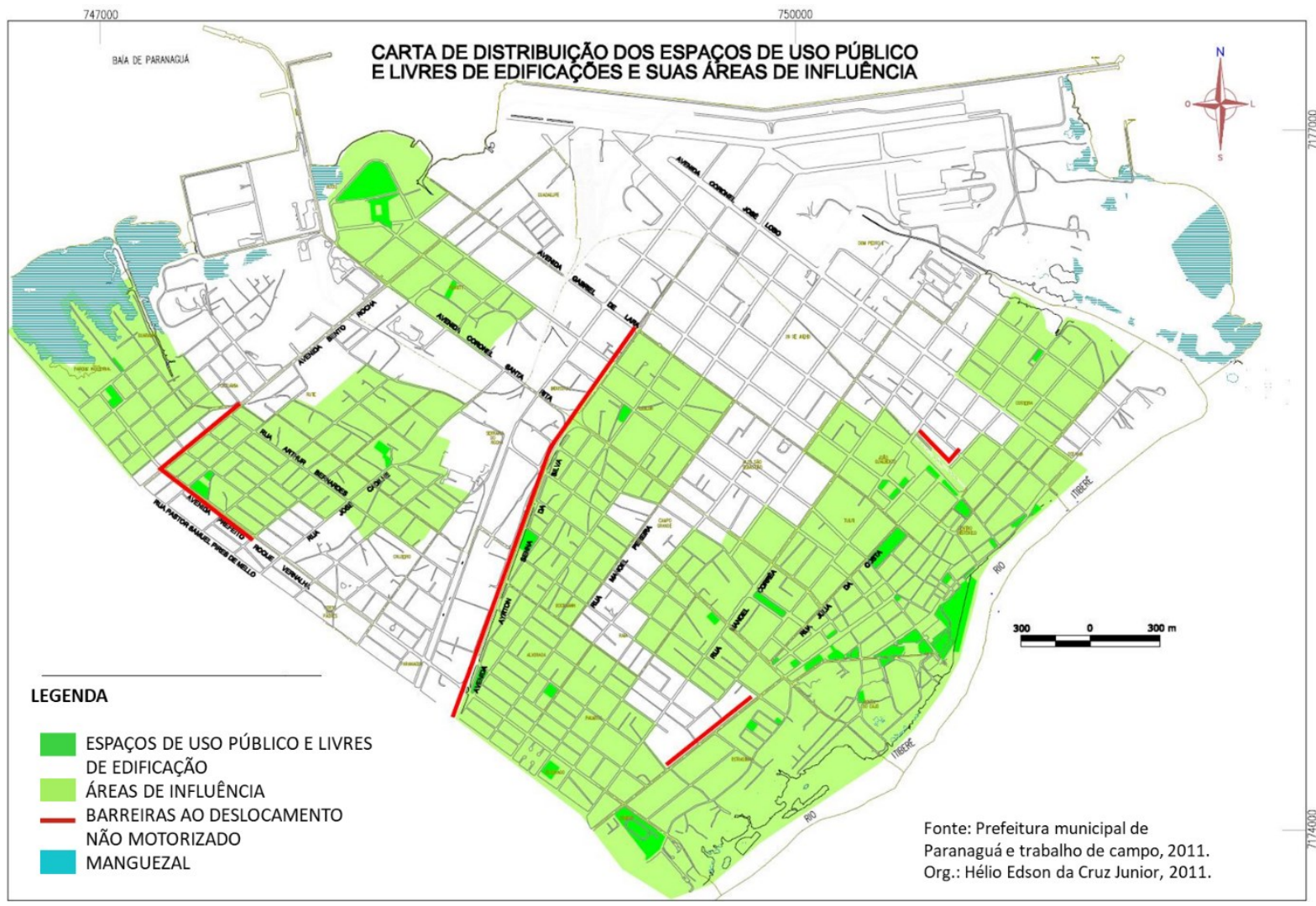

Figura 3 - EUPLES e áreas de influência em segmento urbano de Paranaguá-PR. Fonte: Tonetti, Nucci e Valaski (2012).

No mesmo segmento da área urbana do município de Paranaguá, Tonetti, Nucci e CruzJunior (2011), encontraram 11,35\% de cobertura vegetal. Este levantamento englobou os tipos fisionômicos arbóreo, arbustivo e herbáceo, com pequenas manchas de vegetação distribuídas aleatoriamente pelo interior da área de estudo e grandes manchas na periferia, associadas aos manguezais da Baía de Paranaguá e do Rio Itiberê (Figura 4). 


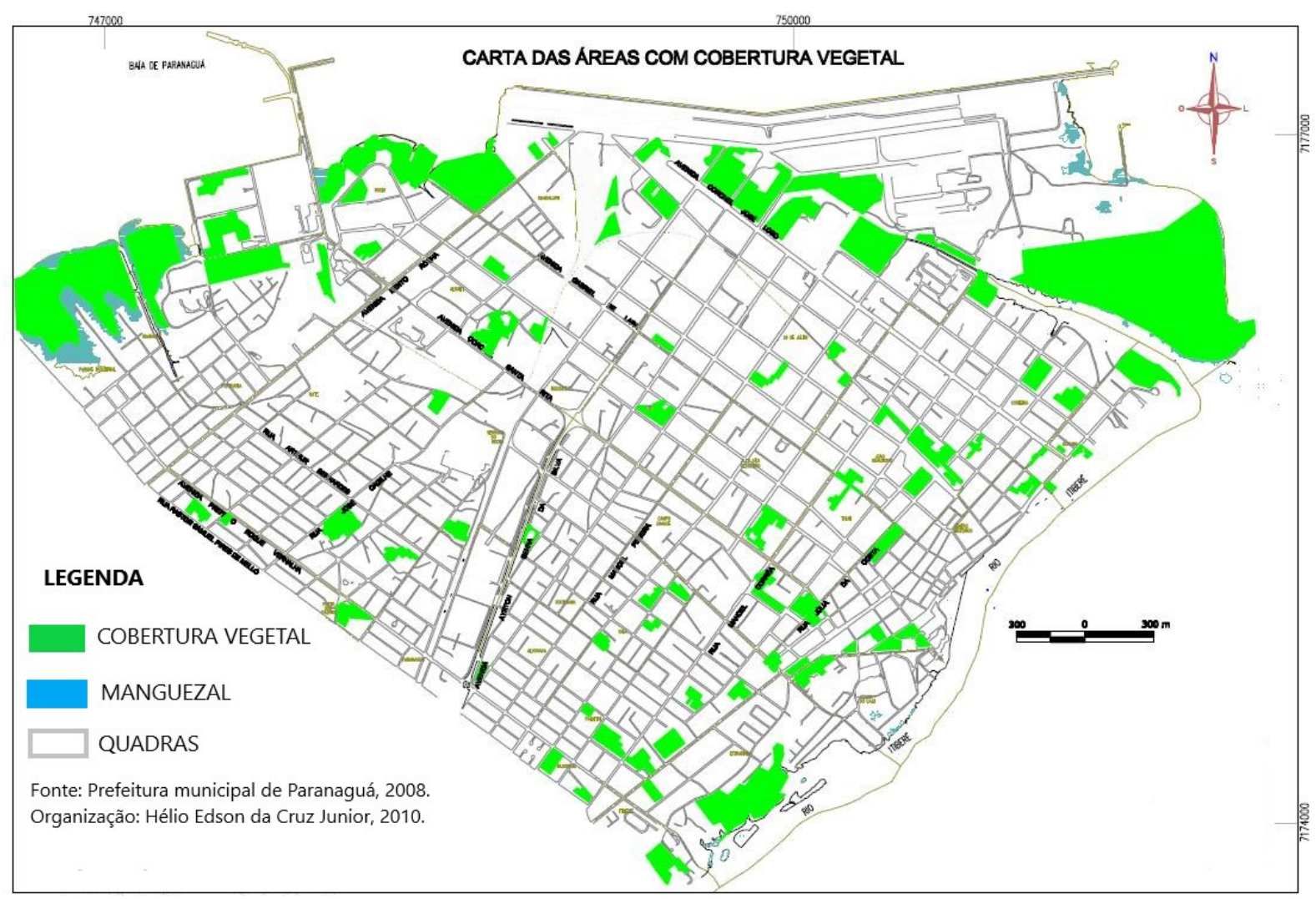

Figura 4 - Cobertura Vegetal em segmento urbano de Paranaguá-PR.

Fonte: Tonetti, Nucci e Cruz-Junior (2011).

Muitos desses espaços com cobertura vegetal podem ser EUPLEVs e por isso exercem função não somente de lazer ou estética, mas também ecológica (COSTANZA et al., 1997; DeGROOT et al., 2002), contribuindo para manutenção da resiliência urbana existente (AHERN, 2013). Contudo, deve-se considerar que todos esses locais com ou sem vegetação devem ser planejados para serem seguros, atrativos e convenientes para motivar as pessoas ao transporte não-motorizado ao trabalho, compras, escolas e outros, além de proporcionar adequadas oportunidades de recreação com qualidade e com acessibilidade pela comunidade (BARTON; TSOUROU, 2000; JACKSON 2003).

\section{Os espaços do Bairro Vila dos Comerciários}

A cobertura vegetal presente no Bairro Vila dos Comerciários da cidade de Paranaguá corresponde a $7,1 \%$ da área total do bairro, abaixo dos $11,35 \%$ de cobertura vegetal constituído por plantas herbáceas, arbustivas e arbóreas encontrados na região central do município de Paranaguá e muito abaixo dos 50\% sugeridos por Attwell (2000), para áreas residenciais pouco 
verticalizadas, que corresponde a condição encontrada no bairro estudado. Attwell (2000) ainda recomenda que $25 \%$ da vegetação do bairro seja do tipo arbórea, o que contrasta com os atuais $2,31 \%$ encontrados. O percentual de vegetação encontrado no bairro corresponde ao deserto florístico comentado por Nucci (2008) ao enfatizar as perdas na qualidade ambiental no local, decorrentes da presença reduzida de vegetação no local (Tabela 1).

Tabela 1 - Valores da Cobertura Vegetal encontrada no Bairro Vila dos Comerciários no município de

\begin{tabular}{ccc}
\multicolumn{3}{c}{ Paranaguá-PR. } \\
\hline INDICADOR & ÁREA $\left(\mathbf{m}^{\mathbf{2}}\right)$ & ÁREA (\%) \\
\hline Arbórea/Arbustiva & 19.228 & 2,3 \\
\hline Arbustiva/Herbácea & 39.726 & 4,78 \\
\hline Total de vegetação & $\mathbf{5 8 . 9 5 4}$ & $\mathbf{7 , 1 0}$ \\
\hline \multicolumn{2}{c}{} \\
\hline Total do bairro & 829.399 & 100 \\
\hline
\end{tabular}

Fonte: os autores.

No bairro Vila dos Comerciários foram encontrados 2 EUPLEs e 74 manchas de Cobertura Vegetal, sendo 26 delas com vegetação arbórea/arbustiva e 48 com vegetação arbustiva/herbácea (Figura 5).

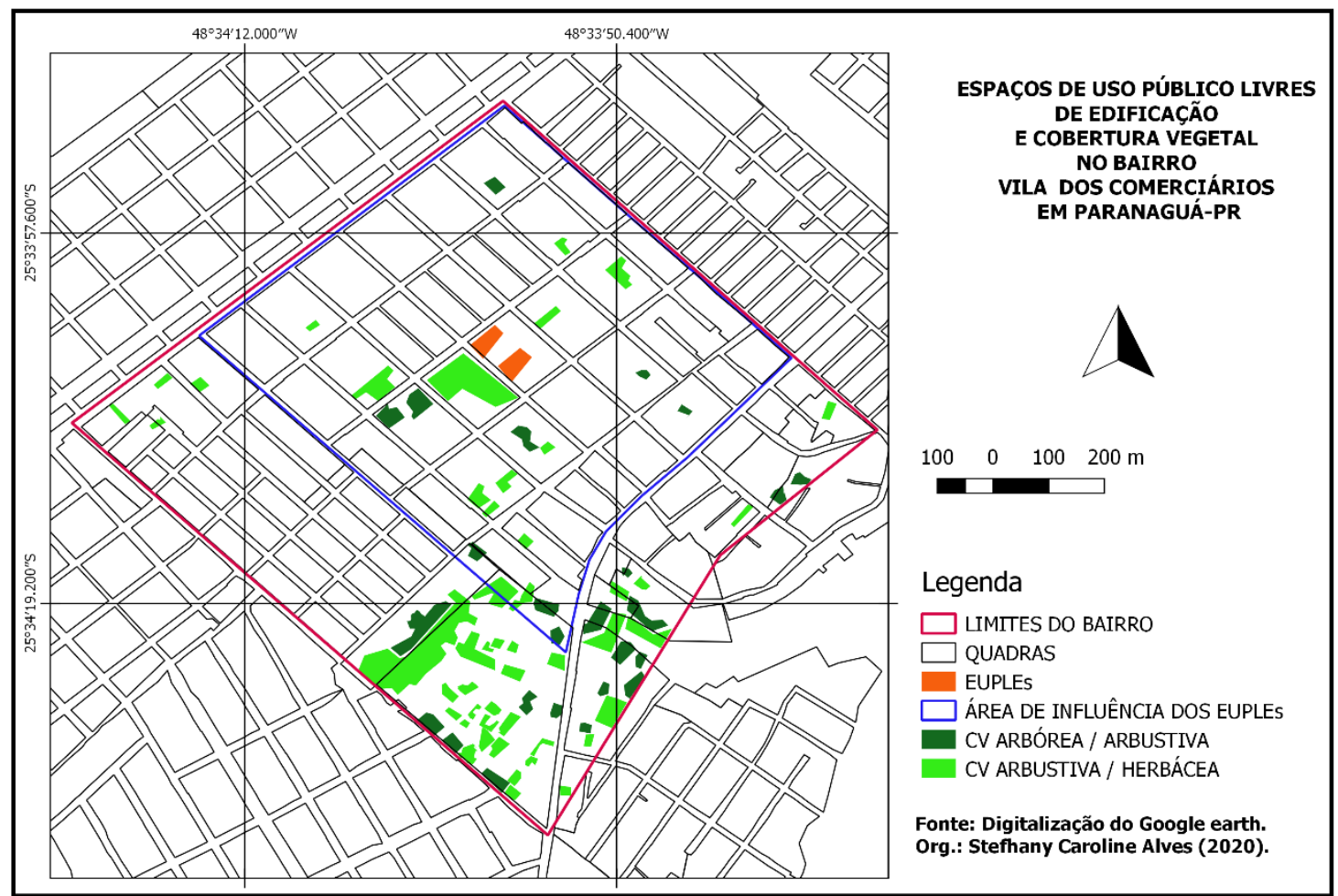

Figura 5 - EUPLEs e Cobertura Vegetal no Bairro Vila dos Comerciários - Paranaguá-PR. Fonte: os autores. 
Sobre a distribuição das manchas de cobertura vegetal no bairro, há certa concentração de pequenas manchas na porção sul e de algumas maiores na região central, entorno dos EUPLEs (Figura 5). Essas manchas de vegetação estão principalmente relacionadas com a presença de terrenos baldios no bairro. Isto significa que não fazem parte de um sistema de cobertura vegetal oficial do município que possa garantir sua permanência. Esses terrenos podem, ainda, ser edificados e reduzir ainda mais o percentual de vegetação no bairro, e a capacidade de resiliência local pela redução dos serviços ecossistêmicos como a redução dos efeitos térmicos e dos alagamentos no verão (AHERN, 2013). Esta condição torna-se mais evidente se considerarmos a densidade das edificações nos lotes do bairro, observada durante a coleta de dados. São lotes pequenos com edificações ocupando praticamente toda a área, principalmente na região oeste (Figura 2).

Os EUPLEs estão situados próximos do centro do bairro, sendo um ponto positivo para a abrangência da sua área de influência. Visto que pode atingir grande parte do bairro, contudo, não contemplando as partes periféricas do sul, leste e oeste do bairro, considerando o raio de influência de 300 metros (TONETTI; NUCCI; VALASKI, 2012; MISAEL, 2019).

Nas observações in loco realizadas nesses EUPLEs, não foram identificadas infraestruturas instaladas para o lazer. Há indicações de que os locais sejam utilizados para jogos na areia, como futebol, por exemplo. Isto sugere que crianças e adolescentes são os principais usuários desses espaços. Desta forma, há deficiência na diversidade e qualidade da oferta desses espaços no bairro Vila dos Comerciários. Ainda, a ausência de outras indicações oficiais no local sugerem que estes espaços podem não ser públicos e se forem não fazem parte da lista dos espaços de lazer da prefeitura municipal de Paranaguá.

Nas situações observadas, é evidente que o planejamento e gestão dos espaços estão relacionados aos gestores municipais e nesse sentido, comentam Nucci e Presotto (2009, p. 89):

Compete ao Poder Público planejar, criar e ajudar a manter ambientes agradáveis e estéticos, além de acomodações e instalações variadas, de modo a facilitar a cada pessoa fazer escolhas acertadas de lazer, segundo o seu gosto e sob a própria responsabilidade.

O cenário do bairro Vila dos Comerciários é uma amostra do que ocorre nos demais bairros do município e os resultados reforçam a necessidade de gestão dos espaços com conhecimento social e ambiental para prover bem-estar aos residentes. 


\section{CONSIDERAÇÕES FINAIS}

O presente trabalho de pesquisa feito no bairro Vila dos Comerciários no Município de Paranaguá-PR mostrou que o bairro não possui um planejamento adequado que vise o bemestar físico ou ambiental dos moradores. Os espaços de uso público e livres de edificações não possuem estruturas instaladas e não atendem a todas as faixas etárias dos residentes, evidenciando a ausência de diversidade e da qualidade desses espaços. O índice de Cobertura Vegetal está abaixo dos indicados, o que causa perdas da qualidade do ambiente com possíveis desiquilíbrios nos processos ambientais.

Todos os bairros da cidade de Paranaguá devem ter um planejamento adequado para atender a população. Um estudo mais aprofundado, com análise histórica e entrevistas, é necessário para entender e identificar as reais necessidade dos moradores, bem como as limitações do bairro em si, para planejar locais de Uso Público Livres de Edificação com Vegetação de qualidade e eficientes.

\section{REFERÊNCIAS}

ADLER, F. R.; TANNER, C.J. Ecossistemas urbanos: princípios ecológicos para o ambiente construído. São Paulo: Oficina de Textos, 2015.

AHERN, J. Urban landscape sustainability and resilience: the promise and challenges of integrating ecology with urban planning and design. Landscape Ecology, v. 28, p. 1203-1212, 2013.

ATTWELL, K. Urban land resources and urban planting - case studies from Denmark. Landscape and Urban Planning, v.52, p.145-163, 2000.

BARTON, H.; TSOUROU, C. Health urban planning: A WHO guide to planning for people. Londres: Spon Press, 2000.

BRASIL. Estatuto da Cidade. 3 ed. Brasília: Senado Federal, Subsecretaria de Edições Técnicas, 2008.

BRASIL. Lei complementar $n^{0}$ 12.651, de 25 de maio de 2012. Diário Oficial da União, Brasília, DF, n. 137, 28 mai. 2012. Seção 1, p. 1.

BUCCHERI-FILHO, A.T. O planejamento dos parques no município de Curitiba, PR: planejamento sistemático ou planejamento baseado em um modelo oportunista? Caminhos de Geografia Uberlândia, v.13, n.41, p.206-222, 2012. 
CAVALCANTI, I.F.A.; FERREIRA, N.J. (Orgs). Climas das regiões brasileiras e variabilidade climática. São Paulo: Oficina de Textos, 2021.

CAVAlHEIRO, F.; NUCCI, J. C.; GUZZO, P.; ROCHA, Y. T. Proposição de terminologia para o verde urbano. Boletim Informativo da Sociedade Brasileira de Arborização Urbana, v. 7, n. 3, p. 7-7, 1999.

CAVAZZANI, A.L.M.; GOMES, S.A.R. (Orgs). Memória histórica de Morretes. Curitiba: Editora UFPR, 2017.

CONSTANZA, R.; D'ARGE, R.; GROOT, R.; FARBER, S.; GRASSO, M.; HANNON, B.;LIMBURG, K.; NAEEM, S.; O'NEILL, R.V.; PARUELO, J.; RASKIN, R.G.; SUTTON, P.; BELT, M. The value of the world's ecosystem services and natural capital. Nature, v.387, p.253-260, 1997.

COVIZZI, M. C.; CAMARGO, D. M.; GOBBI, E. S. Fotointerpretação aplicada à análise das alterações do uso e cobertura da terra e a situação das áreas de preservação permanente. In: PEREZ FILHO, A.; AMORIM, R. R. (Org.). Os Desafios da Geografia Física na Fronteira do Conhecimento. Campinas: Instituto de Geociências - UNICAMP, 2017, v. 1, p. 264-276, 2017.

CUNICO, C. (Org.) Zoneamento Ecológico-Econômico do Estado do Paraná. Curitiba: ITCG, 2016.

HERZOG, C. Cidades para Todos: (re)aprendendo a conviver com a Natureza. Rio de Janeiro: Mauad X: Inverde, 2013.

HOUGH, M. Naturaleza y ciudad: planificacion urbana y processos ecologicos. Barcelona: G. Gilli, 1998.

IPARDES. Instituto Paranaense de Desenvolvimento Econômico e Social. Caderno Estatístico do Município de Paranaguá-PR. 2020. Disponível em: http://www.ipardes.gov.br/cadernos/Montapdf.php?Municipio $=83200 \& b t O k=0 k$. Acesso em: 30 mar. 2020.

IPHAN - Instituto do Patrimônio Histórico e Artístico Nacional. Centro histórico de Paranaguá é tombado. Disponível em: http://portal.iphan.gov.br/portal/montarDetalheConteudo.do?id=14875\&sigla=Noticia\&retorn $\mathrm{o}=$ detalheNoticia. Acesso em: 22 fevereiro 2010.

JACKSON, L. E. The relationship of urban design to human health and condition. Landscape and Urban Planning, v. 64, p. 191-200, 2003.

LATOUR, B. Jamais fomos modernos. 3 ed. Rio de Janeiro: Editora 34, 2013.

MISAEL, G. Y. M. Espaços de uso público, livres de edificação e com vegetação (EUPLEVs) no município de Cornélio Procópio-PR. 2019. 112f. Dissertação (Mestrado em 
Geografia) - Setor de Ciências Exatas e da Terra, Universidade Federal do Paraná, Curitiba, 2019.

MONTEIRO, C. A. F. Geossistemas: a História de uma Procura. São Paulo: Contexto, 2000.

MOURA, A.R.; NUCCI, João Carlos. Cobertura Vegetal em Áreas Urbanas-o caso do Bairro de Santa Felicidade, Curitiba/PR. Revista Geografia. Ensino \& Pesquisa, v. 12, p. 1682-1698, 2008.

NUCCI, J. C. Qualidade Ambiental e Adensamento Urbano: um estudo de ecologia e planejamento da paisagem aplicado ao distrito de Santa Cecília (MSP). 2 ed. Curitiba: Edição do autor, 2008.

PARANAGUÁ. Lei Complementar n⿳0 068, de 23 de agosto de 2007. Institui o Plano Diretor de Desenvolvimento Integrado no Município de Paranaguá. Disponível em: https://leismunicipais.com.br/a/pr/p/paranagua/lei-complementar/2007/6/60/leicomplementar-n-60-2007-institui-o-plano-diretor-de-desenvolvimento-integrado-estabeleceobjetivos-instrumentos-e-diretrizes-para-as-acoes-de-planejamento-no-municipio-deparanagua-e-da-outras-providencias?q=60. Acesso em: 25 abr 2020.

ROSIN, J.A.R.G.; BENINI, S.M. (org). Cidade sustentável: um conceito em construção. Tupã: Associação Amigos da Natureza da Alta Paulista, 2018.

SANTOS, A. V. Memória histórica da cidade de Paranaguá e seu município. 3. ed. Paranaguá: Câmara Municipal, 1952.

SILVA, L. P.; FARIA, G. G. Análise Multitemporal da Expansão Urbana em Paranaguá/Pr a partir do Sensoriamento Remoto: 1986 - 2017. REVISTA CIENTÍFICA INTERDISCIPLINAR INTERLOGOS , v. 5, p. 91-111, 2019.

SUKOPP, H.; WERNER, P. Naturaleza em las ciudades. Madrid: Ministério de Obras Públicas y Transportes (MOPT), 1991.

TONETTI, E. L.; NUCCI, J. C. Diagnóstico e prognóstico em unidades de paisagem na zona urbana de Paranaguá-PR. In: DIAS, N. S.; SALINAS-CHÁVEZ, E. (Org.). Cartografia biogeográfica e da paisagem. v.2. Tupã: ANAP, 2019, p. 203-228.

TONETTI, E. L.; NUCCI, J. C.; CRUZ JUNIOR, H. E. Cobertura vegetal na área urbana de Paranaguá-PR. In: XIV Simpósio Brasileiro de Geografia Física Aplicada, 2011, Dourados. Dinâmicas Socioambientais, das inter-relações às interdependências. Dourados. Anais... Dourados: UFGD, 2011. v. 1. p. 1-12.

TONETTI, E. L.; NUCCI, J. C.; VALASKI, S. Espaços livres na área urbana de Paranaguá (Paraná, Brasil). Revista da Sociedade Brasileira de Arborização Urbana, v. 7, p. 37-50, 2012.

TRAMUJAS, A. Histórias de Paranaguá: dos pioneiros da Cotinga à porta do Mercosul no Brasil Meridional. Paranaguá: Prefeitura Municipal de Paranaguá, 1996. 